\title{
Efeito do nível de caroço de algodão sobre a digestibilidade da fibra dietética do feno de Tifton 85 (Cynodon spp.) em ovinos
}

\author{
[Effect of level of whole cottonseed on digestibility of dietary fiber in sheep] \\ M.C.P. Rogério, I. Borges, D.A.B. Teixeira, N.M. Rodriguez, L.C. Gonçalves \\ ${ }^{1}$ Departamento de Zootecnia - Escola de Veterinária da UFMG \\ Caixa Postal 567 \\ 30123-970 - Belo Horizonte, MG
}

\section{RESUMO}

Vinte e cinco ovinos machos castrados foram submetidos a um delineamento inteiramente ao acaso para avaliar o efeito do nível de caroço de algodão (Gossypium hirsutum) a uma dieta básica de feno de Tifton 85 (Cynodon spp.). Foram estudados os consumos da matéria seca (MS), matéria orgânica (MO), proteína bruta (PB) e extrato etéreo (EE) por unidade de tamanho metabólico e os coeficientes de digestibilidade da fibra detergente neutro, fibra detergente ácido, hemicelulose e celulose. O experimento foi constituído por cinco dietas e cinco ovinos por tratamento (zero, 12, 24, 35 e 45\% de inclusão de caroço de algodão). Não houve diferenças entre dietas nos consumos de MS e de MO. Os consumos da PB e do EE aumentaram linearmente com os níveis de inclusão de caroço de algodão. A adição do caroço integral de algodão resultou em decréscimo linear dos coeficientes de digestibilidade das frações fibrosas, com exceção da hemicelulose. A utilização do caroço de algodão em dietas para ovinos deve ser limitada a 12 e $24 \%$ do total das rações em razão do maior consumo de EE e PB e, ao mesmo tempo, ao menor dano à digestibilidade das frações fibrosas.

Palavras-chave: caroço de algodão, consumo, digestibilidade, ovinos, Tifton 85

\begin{abstract}
The study aimed to evaluate the influence of increasing levels of whole cottonseed (Gossypium hirsutum) on intake of dry matter (DM), organic matter (OM), crude protein (CP) and ether extract (EE) and apparent digestibility (\%) of neutral detergent fiber (NDF) and acid detergent fiber (ADF), hemicellulose and cellulose of experimental diets based on Tifton 85's hay (Cynodon spp.). Twenty five sheep were randomly allotted to five treatments in a completely randomized design with five replicates. The treatments were formulated to contain zero; 12; 24; 35 and 45\% of whole cottonseed. Higher crude protein and ether extract intakes were observed for $45 \%$ whole cottonseed diets, but no significant differences were observed for dry matter and organic matter intakes. Digestibility coefficients of NDF, ADF and cellulose decreased with inclusion of whole cottonseed, but this was not observed for hemicellulose. Diets containing 12 and $24 \%$ of whole cottonseed presented the best results related to ether extract and crude protein intakes and fibrous fractions digestibility coefficients.
\end{abstract}

Keywords: cottonseed, digestibility, intake, sheep, Tifton 85

Recebido para publicação em 30 de setembro de 2003

Recebido para publicação, após modificações, em 4 de fevereiro de 2004

Apoio financeiro: FAPEMIG, CAPES.

Colaborador: A.G.M. Silva

E-mail:mcpr75@hotmail.com 


\section{INTRODUÇÃO}

O uso de oleaginosas na dieta de ruminantes tem despertado grande interesse, principalmente pela facilidade desses alimentos, seus subprodutos ou mesmo partes da planta, incorporarem óleos às rações, elevando sua densidade energética. Alimentos como o caroço integral de algodão contribuem para elevar os teores protéicos da ração, além de incrementarem os valores de fibras, vantagens que alimentos energéticos, como o milho, não proporcionam.

Devendra e Lewis (1974) comentaram sobre efeitos negativos da inclusão de lipídeos às dietas principalmente com relação à queda da digestibilidade das frações fibrosas. O presente trabalho teve o objetivo de determinar o consumo voluntário de matéria seca (MS), matéria orgânica $(\mathrm{MO})$, proteína bruta $(\mathrm{PB})$ e extrato etéreo (EE) e estudar a digestibilidade das frações fibrosas de dietas com níveis crescentes de caroço integral de algodão em ovinos.

\section{MATERIAL E MÉTODOS}

O trabalho foi conduzido entre 17 de fevereiro e 10 de março de 2000. O caroço integral de algodão (Gossypium hirsutum), proveniente do sul da Bahia, caracterizava-se como do tipo comercial "alto línter", com maior conteúdo de fibra, segundo classificação de Arieli (1998). Usou-se feno da gramínea Tifton 85 (Cynodon spp.), adquirido da empresa Haras Sahara, localizada no município de Matozinhos-MG.

Incluiu-se o caroço integral de algodão nos níveis zero, $10,20,30$ e $40 \%$, como fonte energético-protéica, a uma dieta básica de feno de Tifton 85 picado grosseiramente. Foram utilizados cinco carneiros machos castrados por tratamento, com peso médio de $40 \mathrm{~kg}$, aleatoriamente distribuídos nos tratamentos de acordo com o peso.

Os ovinos foram desverminados, tosquiados e alojados em gaiolas de metabolismo com piso ripado, bebedouro e comedouro em aço inoxidável, saleiro plástico e dispositivos apropriados para colheita de fezes. Os dispositivos, constituídos por baldes de 10 litros cortados em seção oblíqua, serviam de apoio para uma tela com malha de $5 \mathrm{~mm}$ para a separação das fezes e urina. A urina foi recolhida no balde e as fezes em recipientes plásticos de $60 \times 40 \mathrm{~cm}$, colocados sob os baldes.

O período de adaptação dos animais às dietas e às gaiolas foi de 15 dias $\mathrm{e} o$ de colheita (experimental) de sete dias. Os carneiros foram pesados no início do período de adaptação. O peso foi utilizado para o cálculo do consumo em gramas por unidade de tamanho metabólico $\left(\mathrm{kg}^{0,75}\right)$ e conseqüente ajuste da quantidade de sobras.

As dietas, divididas em duas refeições iguais, foram fornecidas às $7 \mathrm{e}$ às $18 \mathrm{~h}$, sempre deixando sobra diária (em matéria seca) entre 15 e $20 \%$ do oferecido. Amostras do alimento oferecido e das sobras foram retiradas diariamente às $6 \mathrm{~h} e$ $30 \mathrm{~min}$, pesadas e guardadas em sacos plásticos. Ao final do período experimental, foi preparada uma amostra composta por animal, seguindo os procedimentos de rotina para experimentos desta natureza. Registrou-se o peso da produção total e fez-se reserva de uma alíquota de $20 \%$ do peso. Ao final do experimento também foi preparada uma amostra composta por animal.

Para as determinações de $\mathrm{MS}, \mathrm{MO}, \mathrm{EE}$ e $\mathrm{PB}$ seguiu-se a metodologia proposta por Official... (1980). Para a quantificação da fibra em detergente neutro (FDN) e fibra em detergente acido (FDA), celulose, hemicelulose e lignina utilizou-se a metodologia descrita por Van Soest et al. (1991). Determinaram-se os coeficientes de digestibilidade da fibra em detergente neutro, fibra em detergente ácido, celulose e hemicelulose.

O delineamento experimental foi inteiramente ao acaso, com cinco tratamentos e cinco repetições. As comparações entre médias foram feitas pelo teste SNK ao nível de 5\%. Foram estimados o coeficiente de correlação entre as variáveis estudadas e a regressão do consumo e dos coeficientes de digestibilidade em relação ao nível de inclusão do caroço de algodão na dieta. Todas as análises foram realizadas utilizando-se o sistema de analises estatísticas e genéticas (Sistema..., 1995).

A composição química e a energia bruta das dietas constam na Tab. 1. 
Tabela 1. Composição química (\%) e energia bruta $(\mathrm{Mkcal} / \mathrm{kg})$ das dietas, segundo o nível de inclusão de caroço de algodão (na matéria seca), para ovinos

\begin{tabular}{lccccc}
\hline & $0 \%$ & $12 \%$ & $24 \%$ & $35 \%$ & $45 \%$ \\
\hline Matéria seca & 88,51 & 88,63 & 88,75 & 88,86 & 88,96 \\
Proteína bruta & 7,81 & 9,98 & 12,16 & 14,15 & 15,96 \\
Extrato etéreo & 2,42 & 4,69 & 6,96 & 9,03 & 10,92 \\
FDN & 86,51 & 80,90 & 75,29 & 70,14 & 65,46 \\
FDA & 55,67 & 52,47 & 49,26 & 46,33 & 43,66 \\
Hemicelulose & 30,84 & 28,43 & 26,02 & 23,82 & 21,80 \\
Celulose & 50,08 & 46,53 & 42,99 & 39,74 & 36,78 \\
Lignina & 5,09 & 5,30 & 5,51 & 5,70 & 5,88 \\
Cinzas & 2,4 & 2,68 & 2,96 & 3,23 & 3,46 \\
Energia bruta & 4,42 & 4,60 & 4,78 & 4,94 & 5,09 \\
\hline
\end{tabular}

\section{RESULTADOS E DISCUSSÃO}

Em função da seletividade dos animais, a pretendida inclusão do caroço integral de algodão (zero, 10, 20, 30 e 40\%) descrita em Material e Métodos foi ajustada e ficou nos níveis arredondados de zero, 12, 24, 35 e 45\%, obtidos a partir da relação feno:caroço observada na Tab. 2.

Tabela 2. Consumo médio diário (CMD) do feno de Tifton 85 e do caroço de algodão (matéria seca) e relação feno:caroço de algodão consumida por tratamento, por ovinos

\begin{tabular}{lccc} 
Tratamento & $\begin{array}{c}\text { CMD feno } \\
(\mathrm{kg})\end{array}$ & $\begin{array}{c}\text { CMD caroço } \\
(\mathrm{kg})\end{array}$ & $\begin{array}{c}\text { Feno:caroço } \\
(\%)\end{array}$ \\
\hline $0 \%$ & 1,036 & 0,000 & $100,0: 0,0$ \\
$10 \%$ & 1,015 & 0,133 & $88,41: 11,59$ \\
$20 \%$ & 0,809 & 0,248 & $76,54: 23,46$ \\
$30 \%$ & 0,741 & 0,396 & $65,17: 34,83$ \\
$40 \%$ & 0,529 & 0,434 & $54,93: 45,07$ \\
\hline
\end{tabular}

Antes de ser discutido o efeito da gordura sobre a digestibilidade das porções fibrosas faz-se necessário tecer alguns comentários sobre os valores de consumo encontrados neste trabalho, já que existe uma relação intrínseca entre o consumo e o coeficiente de digestibilidade das frações fibrosas.

A Tab. 3 mostra o consumo, expresso em $\mathrm{g} / \mathrm{kg}^{0,75}$, de matéria seca, matéria orgânica, proteína bruta e extrato etéreo. O consumo médio diário de matéria seca foi de $67,55 \pm 5,06 \mathrm{~g}$ de $\mathrm{MS} / \mathrm{kg}^{0,75}$ (Tab. 3). Karalazos et al. (1992) obtiveram valor médio de $76,5 \mathrm{~g} / \mathrm{kg}^{0,75}$. Mahgoub et al. (2000) observaram consumo médio diário de matéria seca entre 76,5 e $97,5 \mathrm{~g} / \mathrm{kg}^{0,75}$. Conforme o Nutrient... (1985), a exigência nutricional de mantença de ovinos adultos é de 53,19 gramas de $\mathrm{MS} / \mathrm{kg}^{0,75} / \mathrm{dia}$.

Não houve efeito negativo da inclusão do caroço de algodão (adição de extrato etéreo) sobre o consumo de matéria seca e de matéria orgânica, confirmando os resultados encontrados por Souto et al. (1990) e Sridhar et al. (1996). Rode et al. (1985) postularam haver influência negativa da suplementação com gordura sobre o consumo de matéria seca e Mahgoub et al. (2000) verificaram aumento de consumo com o aumento de proporção de grãos na dieta. Essas controvérsias, segundo Palmquist e Jenkins (1980), são normais em função do impacto da gordura na dieta ser influenciado pela fonte, processamento e nível de inclusão do suplemento.

Tabela 3. Consumo médio diário $\left(\mathrm{g} / \mathrm{kg}^{0,75}\right)$ da matéria seca, matéria orgânica, proteína bruta e extrato etéreo das dietas segundo o nível de inclusão de caroço de algodão, por ovinos

\begin{tabular}{lcccccc}
\hline Variável & $0 \%$ & $12 \%$ & $24 \%$ & $35 \%$ & $45 \%$ & $\begin{array}{c}\text { Coeficiente de } \\
\text { variação (\%) }\end{array}$ \\
\hline Matéria seca & $72,29 \mathrm{a}$ & $64,75 \mathrm{a}$ & $72,30 \mathrm{a}$ & $67,86 \mathrm{a}$ & $60,53 \mathrm{a}$ & 11,97 \\
Matéria orgânica & $69,11 \mathrm{a}$ & $62,22 \mathrm{a}$ & $69,64 \mathrm{a}$ & $65,26 \mathrm{a}$ & $58,13 \mathrm{a}$ & 12,09 \\
Proteína bruta & $6,10 \mathrm{~b}$ & $6,75 \mathrm{~b}$ & $9,31 \mathrm{a}$ & $10,15 \mathrm{a}$ & $10,00 \mathrm{a}$ & 12,95 \\
Extrato etéreo & $1,92 \mathrm{~d}$ & $3,13 \mathrm{c}$ & $5,23 \mathrm{~b}$ & $6,41 \mathrm{a}$ & $6,82 \mathrm{a}$ & 14,33 \\
\hline
\end{tabular}

Médias com letras iguais na mesma linha não diferem entre si pelo teste SNK $(\mathrm{P}>0,05)$.

O consumo de proteína bruta mostrou-se similar nos ovinos que receberam 24,35 e $45 \%$ de caroço integral de algodão e foi superior aos níveis de zero e $12 \%$. Essa resposta provavelmente aconteceu em função da maior seletividade dos animais (aumento do consumo do caroço de algodão e preferência por folhas às hastes do feno de Tifton 85) na tentativa de atenderem aos requisitos nutricionais e/ou ingerirem material mais palatável. 
A análise de regressão indicou que a resposta do consumo de proteína por $\mathrm{kg}^{0,75}$ à adição crescente de caroço de algodão foi linear e ascendente $(\mathrm{P}<0,0001)$, correspondendo à equação $\mathrm{y}=$ $6,2225+0,112 \times\left(R^{2}=0,65\right)$. Para as variáveis matéria seca e matéria orgânica as equações não foram mostradas por apresentarem valores de $\mathrm{R}^{2}$ abaixo de 0,16 , de pouca confiabilidade.

O consumo de extrato etéreo elevou-se com a inclusão do caroço atingindo o máximo com os níveis 35 e 45\% (Tab. 3). Luginbuhl et al. (2000) mostraram aumentos no consumo de extrato etéreo de ordem cúbica. Segundo Mahgoub et al. (2000), o aumento na densidade energética é comumente associado ao consumo mais alto em extrato etéreo. Os resultados confirmam, portanto, a importante contribuição protéica e energética advinda do caroço integral de algodão às dietas experimentais. A resposta do consumo de extrato etéreo à adição crescente de caroço de algodão foi linear $\mathrm{e}$ ascendente $(\mathrm{P}<0,0001)$, correspondendo à equação: $\mathrm{y}=2,0848+0,1308 \mathrm{x}$ $\left(\mathrm{R}^{2}=0,87\right)$. Anderson et al. (1980) e Villela et al. (1996) verificaram elevações do consumo de extrato etéreo até o nível de $30 \%$ de inclusão de caroço de algodão sem influência no consumo de matéria seca. Considerando o consumo e a digestibilidade, é possível tirar uma conclusão mais acertada sobre o adequado nível de inclusão do caroço integral de algodão em dietas para ovinos. É importante observar os efeitos da inclusão crescente de gordura sobre a digestibilidade das frações fibrosas dietéticas (Devendra e Lewis, 1974).

Houve decréscimo da digestibilidade da FDN, FDA e da celulose a partir do incremento dos níveis de caroço de algodão dietéticos (Tab. 4). Para a FDN, os maiores coeficientes de digestibilidade ocorreram nos tratamentos zero, 12 e $24 \%$ de inclusão de caroço. A partir da inclusão de $35 \%$ de caroço de algodão ou $9,0 \%$ de lipídeos na matéria seca (superior aos 8\% recomendados por Van Soest, 1994), houve redução da digestibilidade da FDN. Os tratamentos com 35 e $45 \%$ de inclusão do caroço integral de algodão apresentaram os menores coeficientes de digestibilidade. Para a FDA, o tratamento $0 \%$ de inclusão de caroço integral de algodão foi o que resultou na maior digestibilidade, semelhante à do tratamento que incluiu $12 \%$ de caroço, este semelhante à do tratamento de $24 \%$ de inclusão de caroço. Os tratamentos 35 e $45 \%$ de inclusão de caroço apresentaram os mais baixos coeficientes de digestibilidade da FDA. Os coeficientes de digestibilidade da celulose comportaram-se da mesma forma que os encontrados para a FDN (9,0 e 10,9\% de inclusão lipídica na matéria seca nos tratamentos com 35 e $45 \%$ de inclusão de caroço de algodão).

Tabela 4. Coeficiente de digestibilidade (\%) das frações fibrosas das dietas segundo o nível de inclusão do caroço de algodão, para ovinos

\begin{tabular}{lcccccc} 
Variável & $0 \%$ & $12 \%$ & $24 \%$ & $35 \%$ & $45 \%$ & $\begin{array}{c}\text { Coeficiente de } \\
\text { variação (\%) }\end{array}$ \\
\hline FDN & $51,33 \mathrm{a}$ & $50,89 \mathrm{a}$ & $47,34 \mathrm{a}$ & $40,30 \mathrm{~b}$ & $37,36 \mathrm{~b}$ & 9,90 \\
FDA & $49,51 \mathrm{a}$ & $46,77 \mathrm{ab}$ & $41,59 \mathrm{~b}$ & $33,39 \mathrm{c}$ & $30,45 \mathrm{c}$ & 10,41 \\
Hemicelulose & $54,59 \mathrm{a}$ & $58,93 \mathrm{a}$ & $58,50 \mathrm{a}$ & $53,98 \mathrm{a}$ & $51,22 \mathrm{a}$ & 15,56 \\
Celulose & $59,28 \mathrm{a}$ & $59,22 \mathrm{a}$ & $52,91 \mathrm{a}$ & $46,34 \mathrm{~b}$ & $40,95 \mathrm{~b}$ & 8,88 \\
\hline
\end{tabular}

Médias com letras iguais na mesma linha não diferem entre si pelo teste SNK $(\mathrm{P}>0,05)$.

Storry (1981) citou que a inclusão de gordura protegida em níveis superiores a $10 \%$ resultou em diminuição efetiva da digestibilidade da fibra. Relacionando com o que foi comentado anteriormente, é importante salientar que as menores digestibilidades corresponderam aos maiores consumos de extrato etéreo, sugerindo efeito inibidor da gordura sobre a digestibilidade da fibra. A digestibilidade da hemicelulose permaneceu inalterada entre os tratamentos.
Até $24 \%$ de inclusão não houve efeito negativo, porém é importante destacar que nesse nível de inclusão pode ocorrer inibição de digestibilidade da FDN e da celulose, conforme foi observado na digestibilidade da FDA. Acima de 12\% de inclusão de caroço há grande probabilidade de diminuição da digestibilidade da FDA, já que o valor encontrado para esse nível se iguala ao encontrado para $24 \%$. Este último valor é 
comparável aos $15 \%$ recomendados por Pires et al. (1997), com o objetivo de minimizar o efeito depletivo das gorduras sobre a digestibilidade da fibra ruminal.

Nitas e Karalazos (1998) comentaram que a inclusão de níveis superiores a $30,4 \%$ de caroço de algodão a uma dieta composta de milho, farelo de soja, óleo de caroço de algodão, palha de trigo e um composto mineral e vitamínico resultou em decréscimo da digestibilidade da FDN, da FDA, da hemicelulose e da celulose.

As regressões da digestibilidade da FDN $\left(\mathrm{y}=53,147-0,3851 \mathrm{x}, \quad \mathrm{R}^{2}=0,62\right), \quad$ da $\quad$ FDA $\left(\mathrm{y}=50,645-0,5151 \mathrm{x}, \quad \mathrm{R}^{2}=0,77\right) \quad \mathrm{e}$ da celulose $\left(y=61,645-0,4954 x, \quad R^{2}=0,71\right)$ foram linear $e$ descendente, o que reflete correlação negativa entre digestibilidade e nível de inclusão do caroço de algodão. A FDN parece ter sido a menos afetada pela inclusão dos níveis crescentes do caroço de algodão. A queda da digestibilidade da FDA foi evidente. A maior queda da digestibilidade da FDA associada à menor queda da digestibilidade da FDN possivelmente foram responsáveis pela inalterabilidade da digestibilidade da hemicelulose, conforme observações feitas por Rodriguez (1984) com a inclusão de farelo de arroz ao feno de braquiária. Smith e Vosloo (1990) e Luginhbul et al. (2000) verificaram decréscimo significativo da digestibilidade aparente da FDN e da FDA em função da elevação dos níveis de caroço integral de algodão nas dietas. Karalazos et al. (1992) obtiveram queda da digestibilidade aparente da FDN e da FDA no primeiro nível de inclusão de caroço de algodão (17,5\%).

O comportamento da equação de regressão da FDA foi semelhante ao encontrado para a da FDN face à alta correlação existente entre essas duas variáveis $(\mathrm{r}=0,93 ; \quad \mathrm{P}<0,0001) . \quad \mathrm{O}$ comportamento da regressão da celulose foi semelhante ao da FDN e da FDA. A equação de regressão da hemicelulose não foi mostrada em razão de seu baixo $R^{2}(0,08)$.

\section{CONCLUSÕES}

O decréscimo dos coeficientes de digestibilidade da FDN, da FDA e da celulose provavelmente resultaram do efeito negativo dos lipídeos existentes no caroço sobre a digestibilidade da fibra. Recomenda-se a inclusão do caroço integral de algodão em dietas para ovinos em níveis entre 12 e $24 \%$ do total das dietas. Nesse intervalo houve maior consumo de proteína e, ao mesmo tempo, os prejuízos foram menores sobre a digestibilidade das frações fibrosas. Não há explicação sobre a inalterabilidade da digestibilidade da hemicelulose nos diferentes níveis de inclusão de caroço de algodão.

\section{REFERÊNCIAS BIBLIOGRÁFICAS}

ANDERSON, M.J.; LAMB, R.C.; WALTERS, J.L. Comparison of four levels of whole cottonseed for lactating dairy cows. J.Dairy Sci., v.63, p.154-162, 1980.

ARIELI, A. Whole cottonseed in dairy cattle feeding: a review. Anim. Feed Sci. Technol., v.72, p.97-110, 1998.

DEVENDRA, C.; LEWIS, D. The interaction between dietary lipids and fibre in the sheep. 2 . Digestibility studies. Anim. Prod., v.19, p.67-76, 1974

KARALAZOS, A.; DOTAS, D.; BIKOS, J. A note on the apparent digestibility and nutritive value of whole cottonseed given to sheep. Anim. Prod., v.55, p.285-287, 1992.

LUGINBUHL, J.M.; POORE, M.H.; CONRAD, A.P. Effect of level of whole cottonseed on intake, digestibility, and performance of growing male goats fed hay-based diets. J. Anim. Sci., v.78, p.1677-1683, 2000.

MAHGOUB, O.; LU, C.D.; EARLY, R.J. Effects of dietary energy density on feed intake, body weight gain and carcass chemical composition of Omani growing lambs. Small Rumin. Res., v.37, p.35-42, 2000.

NITAS, D.; KARALAZOS, A. Effect of whole cottonseed participation on nutrient and gross energy digestibility of sheep diets with the same protein and fat content. Epith. Zooteh. Epist., v.24, p.83-94, 1997, apud Nutr. Abstr. Rev., (Series B), v.68, p.650, 1998.

NUTRIENT requeriments of sheep. 6.ed. Washington, DC: National Academy, 1985. 99p.

OFFICIAL Methods of Analysis. Washington, DC: AOAC, 1980. 1015p. 
PALMQUIST, D.L.; JENKINS, T. Fat in lactation ration: a review. J. Dairy $S c i$., v.63, p.114, 1980.

PIRES, A.V.; EASTRIDGE, M.L.; FIRKINS, J.L. et al. Effects of heat treatment and physical processing of cottonseed on nutrient digestibility and production performance by lactating cows. $J$. Dairy Sci., v.80, p.1685-1694, 1997.

RODE, L.; WEAKLEY, D.; SATTER, L. Effect of forage amount and particle size in diets of lactating dairy cows on site of digestion and microbial protein synthesis. Can. J. Anim. Sci., v.65, p.101-111, 1985.

RODRIGUEZ, N.M. Valor nutritivo do farelo de arroz para ruminantes. 1984. 127f. Tese (Professor Titular) - Escola de Veterinária, Universidade Federal de Minas Gerais, Belo Horizonte.

SISTEMA de Análises Estatísticas e Genéticas SAEG. Viçosa: UFV, 1995. (Versão 7.0).

SMITH, W.A.; VOSLOO, L.P. Digestibility of diets containing cottonseed and the effect of supplementary lanolin thereon in sheep. South Afr. J. Anim. Sci., v.20, p.216-222, 1990.

SOUTO, P.R.L.; MILAGRES, J.C.; SILVA, M.A. et al. Consumo, digestibilidade, reações fisiológicas e componentes sangüíneos de ovinos submetidos a diferentes temperaturas e a dietas com diferentes níveis de energia. I. Consumo de alimento e ingestão de água. Pesq. Agropec. Bras., v.25, p.1247-1251, 1990.

SRIDHAR, V.; JANARDHANA REDDY, T.; RAGHAVA RAO, E. et al. Nutrient digestibilities as influenced by dietary energy levels in Deccani lambs. Indian J. Anim. Nutr., v.13, p.53-55, 1996.

STORRY, J.E. The effect of dietary fat on milk composition. In: HARESIGN, W. Recent advances in animal nutrition. London, Boston : Butterworths, 1981. P.11-13.

VAN SOEST, P.J. Nutritional ecology of the ruminant. 2.ed. Ithaca, NY: Cornell University, 1994. 476p.

VAN SOEST, P.J.; ROBERTSON, J.D.; LEWIS, B.A. Methods for dietary fiber, neutral detergent fiber, nonstarch polysaccharides in relation to animal nutrition. J. Dairy Sci., v.74, p.3583$3597,1991$.

VILLELA, S.D.J.; FILHO, S.C.V.; SILVA, J.F.C. et al. Caroço de algodão para vacas leiteiras (consumo de nutrientes, produção e composição do leite). Rev. Soc. Bras. Zootec., v.25, p.298-308, 1996. 